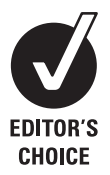

- Additional tables and figures are published online only at http://jmg.bmj.com/content/ vol46/issue9

${ }^{1}$ DIBIT, San Raffaele Scientific Institute, Milano, Italy; ${ }^{2}$ Institute of Molecular Genetics, CNR,

Pavia, Italy; ${ }^{3}$ Department of Pathology and Medical Genetics, University of Pavia, Pavia, Italy;

${ }^{4}$ Department of Computer Engineering and Systems

Science, University of Pavia, Pavia, Italy; ${ }^{5}$ San Raffaele Hospital, Department of Obstetrics and Gynecology, Milano, Italy

Correspondence to: Dr D Toniolo, DIBIT, San Raffaele Scientific Institute, Via Olgettina 58, 20132 Milano, Italy; daniela.toniolo@hsr.it

Received 7 November 2007 Revised 21 February 2008 Accepted 22 February 2008

Published Online First 15 July 2008

\title{
Epigenetic analysis of the critical region I for premature ovarian failure: demonstration of a highly heterochromatic domain on the long arm of the mammalian $\mathrm{X}$ chromosome
}

\author{
F Rizzolio, ${ }^{1}$ T Pramparo, ${ }^{3}$ C Sala, ${ }^{1}$ Z Zuffardi, ${ }^{3}$ L De Santis, ${ }^{5}$ E Rabellotti, ${ }^{5}$ F Calzi, ${ }^{5}$ F Fusi, ${ }^{5}$ \\ R Bellazzi, ${ }^{4}$ D Toniolo ${ }^{1,2}$
}

\section{ABSTRACT}

Background: X chromosome rearrangements defined a critical region for premature ovarian failure (POF) that extended for $>15 \mathrm{Mb}$ in $\mathrm{Xq}$. It has been shown previously that the region could be divided into two functionally distinct portions and suggested that balanced translocations interrupting its proximal part, critical region 1 (CR1), could be responsible for POF through downregulation of ovary expressed autosomal genes translocated to the $\mathrm{X}$ chromosome.

Results and conclusion: This study reports that such position effect can indeed be demonstrated by analysis of breakpoint regions in somatic cells of POF patients and by the finding that CR1 has a highly heterochromatic organisation, very different from that of the euchromatic autosomal regions involved in the rearrangements. The chromatin organisation of the POF CR1 is likely to be responsible for the epigenetic modifications observed in POF patients. The characteristics of CR1 and its downregulation in oocytes may very well explain its role in POF and the frequency of the POF phenotype in chromosomal rearrangements involving $\mathrm{Xq}$. This study also demonstrates a large and evolutionary conserved domain of the long arm of the $\mathrm{X}$ chromosome, largely corresponding to CR1, that may have structural or functional roles, in oocyte maturation or in $\mathrm{X}$ chromosome inactivation.

Many rearrangements and monosomies of the $\mathrm{X}$ chromosome are associated with female infertility. Primary amenorrhoea and streak ovaries are consistent characteristics of $\mathrm{X}$ monosomy, in Turner syndrome, ${ }^{12}$ while premature ovarian failure (POF, OMIM 311360 and 300511), a disorder characterised by amenorrhoea and elevated serum gonadotropin values before the age of 40 years, is associated with partial monosomies and X;autosome balanced translocations. ${ }^{3-5}$ Cytogenetic and molecular analysis of chromosomal rearrangements has defined a critical region for POF on the long arm of the $\mathrm{X}$ chromosome from Xq13.3 to q26/27. ${ }^{67}$ Ovary expressed genes, that are significantly enriched on the mammalian $\mathrm{X},{ }^{8}$ could be involved in the phenotype.

We have shown that the aetiology of $X$ linked POF may be more complex, ${ }^{79}$ as the POF critical region could be split into two functionally different portions, critical region 1 and 2 (CR1 and CR2). Most breakpoints in X;autosome balanced translocations in POF patients were clustered in CR1. However, only deletions involving CR2 were found to be associated with POF, while large interstitial deletions of CR1 were not. These findings suggested that POF CR1 may not carry genes for ovarian function as previously hypothesised and that such genes should be present only in CR2. Indeed, mapping of several breakpoints in the region failed to identify ovary expressed genes that could be responsible for POF. Such genes were found at the autosomal breakpoints, in six cases studied. ${ }^{9}$

Based on our data we suggested that POF CR1 may have an ovary specific conformation that will result in a position effect on autosomal genes when involved in balanced translocations. Our suggestion was strengthened by the observation that genes in the POF critical region undergo a global downregulation of expression in oocytes, compared to autosomal genes, that is not found elsewhere along the $\mathrm{X}$ chromosome. ${ }^{9}{ }^{10}$ The downregulation of $X$ linked gene expression in oocytes is unique as all other cell types and tissues analysed appeared instead to be upregulated in respect to the autosomes, ${ }^{11}$ possibly to reach an equal level of gene expression between the $\mathrm{X}$ chromosome and the autosomes. ${ }^{12}$ In oocytes, where two active $\mathrm{X}$ chromosomes are present, the same mechanisms may not be required, and other molecular changes, possibly essential to go through the long meiotic prophase, may become more relevant. Several mouse mutants carrying knock out (KO) in genes for chromatin modifications ${ }^{13}{ }^{14}$ presented well defined meiotic defects in oocytes and/or spermatids that demonstrated the importance of a proper chromatin modifications, chromosomal structure and control of gene expression during meiosis. Based on the available evidence we proposed that oocyte expressed genes translocated to the critical region of the active $\mathrm{X}$ chromosome may undergo downregulation of their expression driven by the flanking X chromosome, similar to the mechanisms described for Drosophila position effect variegation. ${ }^{15} 16$ This may result in the unique and very peculiar association of the POF phenotype to $\mathrm{X}$; autosome balanced translocations in CR1.

We present here a characterisation of CR1 in somatic tissues and in the ovary, in human and mouse, that indicates that CR1 is a highly heterochromatic region of the genome and indeed very different from the autosomes involved in POF associated balanced translocations; it may thus alter the epigenetic modifications of autosomal genes through a position effect detectable to some extent also in somatic cells. 


\section{MATERIALS AND METHODS}

\section{Cell lines and fluorescence in situ hybridisation mapping}

Patients, lymphoblastoid cell lines and fluorescence in situ hybridisation (FISH) mapping have been previously described.'

\section{Chromatin preparation and immunoprecipitation}

Lymphoblastoid cell lines were fixed in 1\% formaldehyde, as described by the Jenuwein laboratory (http://www.epigenomenoe.net/researchtools/protocol.php?protid=9\#ref_nav). The reaction was quenched with $125 \mathrm{mM}$ glycine and the cells resuspended in lysis buffer (1\% SDS, $10 \mathrm{mM}$ EDTA pH8, $50 \mathrm{mM}$ Tris- $\mathrm{HCl} \mathrm{pH}$ 8.1, $1 \mathrm{mM}$ PMSF (phenylmethylsulphonyl fluoride) and sonicated with a XL2020 sonicator microtip (Misonix Inc, Farmingdale, New York, USA) at 20\% power for $150 \mathrm{~s}$, to break DNA in chromatin to a size between 500 2000 bp. Chromatin was diluted 10 times in DB buffer $(1 \%$ triton, 2 mM EDTA pH 8, $150 \mathrm{mM} \mathrm{NaCl}, 20 \mathrm{mM}$ Tris- $\mathrm{HCl} \mathrm{pH}$ 8.1, 1 mM PMSF). 100/200 $\mu \mathrm{g}$ of chromatin was immunoprecipitated with $2 \mu \mathrm{l}$ of antibody specific for AcH3 (Upstate Biotechnology, Billerica, Massachusetts, USA) (UB 06-559), $5 \mu \mathrm{l}$ AcH4 (UB 06-866) and $5 \mu \mathrm{l} 2 \mathrm{MK} 4 \mathrm{H3}$ (UB 07-030), overnight at $4^{\circ} \mathrm{C}$ and then mixed with $20 \mu$ of protein A sepharose beads (Amersham, UK) saturated overnight at $4^{\circ} \mathrm{C}$ with $500 \mu \mathrm{g}$ of salmon sperm DNA and $100 \mu \mathrm{g}$ of BSA, and incubated for $3 \mathrm{~h}$ at $4^{\circ} \mathrm{C}$ with gentle rocking. In parallel, immunoprecipitations (IPs) with an unrelated antibody (anti-urokinase plasminogen activator receptor) or no antibodies (mock) were also performed as control. Beads were washed five times with wash buffer (0.1\% SDS, 1\% triton, $150 \mathrm{mM} \mathrm{NaCl}, 20 \mathrm{mM}$ Tris- $\mathrm{HCl} \mathrm{pH}$ 8.1, $1 \mathrm{mM}$ PMSF) and three times with final wash buffer $(0.1 \%$ SDS, 1\% triton, $2 \mathrm{mM}$ EDTA, $500 \mathrm{mM} \mathrm{NaCl}, 20 \mathrm{mM}$ Tris- $\mathrm{HCl} \mathrm{pH}$ 8.1, $1 \mathrm{mM}$ PMSF). Bound chromatin was eluted with 1\% SDS and $0.5 \mu \mathrm{g} / \mu \mathrm{l}$ proteinase $\mathrm{K}$ for $3 \mathrm{~h}$ at $50^{\circ} \mathrm{C}$. DNA was decrosslinked overnight at $65^{\circ} \mathrm{C}$ and purified by phenol/chloroform extraction.

\section{Bacterial artificial chromosome microarray preparation and hybridisation}

The bacterial artificial chromosomes (BACs) listed in supplemental table S1 were spotted on coverslips with the Spectral Genomics spotter (www.spectralgenomics.com). Each spot was replicated eight times. Salmon sperm and Drosophila DNA were spotted as negative controls. Male and female genomic DNA were positive controls. The array also contained control BACs from chromosome 16p13, previously shown as an open chromatin domain. ${ }^{17}$ BACs were random amplified as described (www.sanger.ac.uk) with primers designed to avoid amplification of bacterial DNA. To validate the amplification of the BAC clones, we amplified 19 random sequence tag sites (STS). All the polymerase chain reactions (PCRs) successfully amplified DNA of the expected size from the expected BAC clones (not shown).

Chromatin was amplified as described by the Farnham laboratory (http://www.genomecenter.ucdavis.edu/farnham/ protocol.html) and products were run on agarose gel for quality assessment. Total genomic DNA was digested with EcoRI. Probe DNA was labelled with cyanine3 (Cy3) or cyanine5 (Cy5) dye (BioPrime DNA labeling System, Invitrogen, Carlsbad, California, USA). 0-5-1 $\mu \mathrm{g}$ of the two DNAs to compare, labelled in the two opposite ways, were co hybridised with $50 \mu \mathrm{g}$ of human COT1 DNA in $45 \mu$ l of hybridisation buffer in a hybridisation chamber (Corning, New York, USA) at $42^{\circ} \mathrm{C}$ overnight. Coverslips were scanned and analysed with the Genechip software and data were normalised with local background option. ${ }^{18}$ Ratios were calculated between the hybridisation values obtained for IP and for input DNA, labelled with both dye combinations. As a quality control, the array was first hybridised to male and female DNAs (supplemental figure S2 available online).

\section{Real-time PCR and data analysis}

IP DNA was analysed by real-time PCR with Syber Green Universal Mix in a Light Cycler (Roche Diagnostic, Basel, Switzerland). The PCR primers are listed in supplemental table S3. Total DNA, IP DNA and mock IP DNA were quantified using picogreen (Molecular Probes, Carlsbad, California, USA) and equal amounts of DNA (0.5 ng) were used in PCR. Samples were run in duplicate and each experiment was repeated two to three times, on independent chromatin preparations. Data quantification was done as described by Litt et al. ${ }^{19}$ In brief, the Ct (threshold cycle) was determined and the fold increase was calculated as $2^{\text {(inputCt-IPCt) }}$. All the values were corrected for nonspecific signal, by subtracting the values of mock IP.

Reverse transcriptase (RT) real-time PCR was conducted as described $^{9}$; $\mathrm{p}$ values were calculated as two tailed Student t test.

\section{Bioinformatics analysis}

Gene expression data were obtained from the GNF Symatlas database v1.2.4 (http://symatlas.gnf.org/SymAtlas/): data was from Mouse geneAtlas GNF1M, gcRMA. $\mathrm{AD}^{20}$ was used as a measure of the expression. Only genes presenting average difference $(A D) \geqslant 200$ (as described in Su et $a^{20}$ at least in one of the tissues analysed) were considered in the calculation.

The number of genes and of CpG islands were downloaded from NCBI (human build 36.2, mouse build 37.1, http://www. ncbi.nlm.nih.gov/mapview). LINEs, SINEs and GC content were downloaded from the UCSC genome browser ( $\mathrm{mm} 8$ and hg18, http://genome.ucsc.edu).

Global histone methylation data from Barski et al ${ }^{21}$ were downloaded from the summary windows, displaying the number of tags in $200 \mathrm{bp}$ windows, except for CTCF where 400 bp windows were considered. A cut-off $>1$ tag was applied to eliminate background signals.

\section{RESULTS}

\section{Specific downregulation of gene expression in the POF CR1 in} oocytes

We previously showed that the global downregulation of the active $\mathrm{X}$ chromosome occurring in mammalian oocytes ${ }^{10}{ }^{11}$ was due almost exclusively to the POF critical region as a whole. ${ }^{9}$ We further analysed the region in the mouse where the CR1 syntenic region, from $101-128 \mathrm{Mb}$, is contained in a large human-mouse syntenic region, from 62.8-114.4 Mb in human and from 91.3$142.8 \mathrm{Mb}$ in the mouse (NCBI build 37) (figure 1). As in human, the mouse region is gene poor (figure $1 \mathrm{~A}$ ), and enriched in LINE sequences. LINEs represent $40.48 \%$ of the region compared to $19.2 \%$ in the whole genome, while SINEs are reduced to $3.4 \%$ compared to $8.2 \%$ in the whole genome. ${ }^{22}$

Gene expression was analysed by determining the average level of gene expression/ $\mathrm{Mb}$ along the $\mathrm{X}$ chromosome. The dataset utilised was from the SymAtlas database that contains a normalised set of expression data on many different tissues (http://symatlas.gnf.org/SymAtlas/). In figure $1(\mathrm{~B}-\mathrm{H})$ the results of the analysis of oocytes, fertilised eggs, blastocyst and 6.5 day embryos (E6.5), as well as a number of adult tissues (whole ovary, hypothalamus and lung), are shown. Gene expression in a large portion of the human-mouse syntenic 

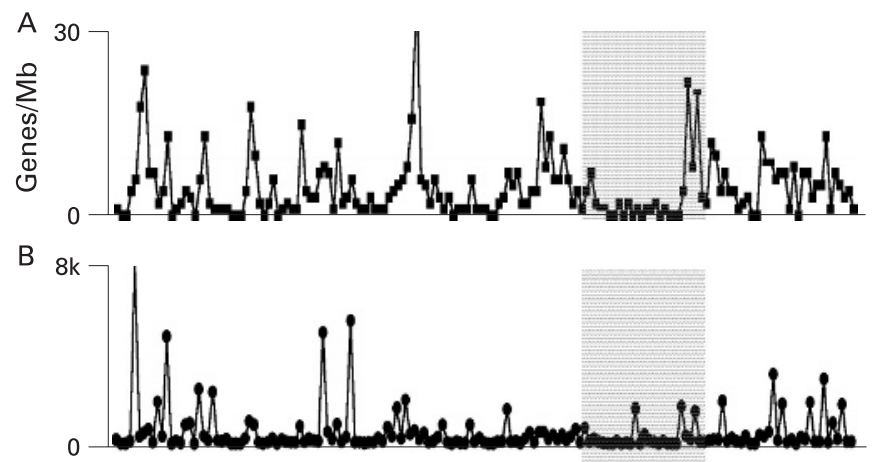

C 8
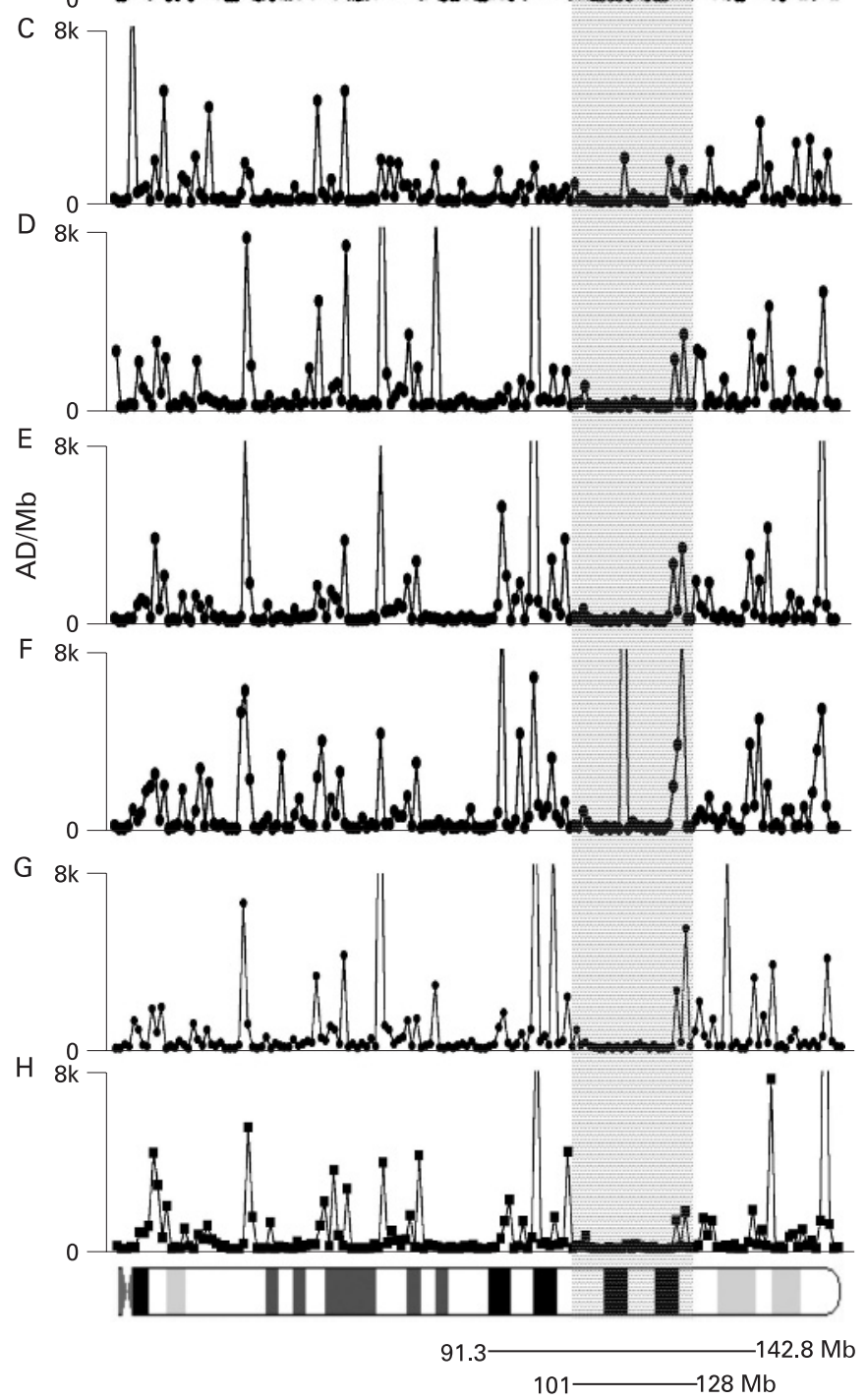

Figure 1 Bioinformatics analysis of $X$ chromosome gene expression in different mouse tissues. (A) Number of genes/Mb calculated as described in Materials and methods. The average gene expression/Mb in (B) oocytes, (C) fertilised eggs, (D) blastocyst, (E) embryo at 6.5 days, (F) ovary, (G) hypothalamus, and (H) lung was calculated from the sum of the normalised GNF expression values for each $\mathrm{Mb}$ along the $\mathrm{X}$ chromosome, divided for the number of genes/Mb. The region corresponding to the critical region 1 (CR1) is boxed. Dotted lines indicate the human/mouse syntenic region and the critical region. Below the position in $\mathrm{Mb}$ the limits of the syntenic regions are indicated.

region (from $85 \mathrm{Mb}$ to $132 \mathrm{Mb}$ ), larger than CR1, appeared specifically downregulated in oocyte and fertilised eggs compared to the rest of the chromosome. It is expressed at a higher level from the blastocyst stage and in all adult tissues. This is particularly evident from the analysis of the regions immediately flanking CR1 (85-103 Mb and 124-132 Mb) that are enriched in genes, both in human and in the mouse (figure 1).

Comparative analysis of the POF CR1 and of two autosomal regions involved in POF associated balanced translocations The POF CR1 spans Xq21 and overlaps with a gene poor region extending from 76-98 Mb (NCBI Build 36.1) of the human X chromosome (figure 2A). The average gene content of CR1 was 3.22 genes $\mathrm{Mb}$, about one third of that of the whole $\mathrm{X}$ chromosome (8.6 genes/Mb). As shown in figure 2 (B and $\mathrm{C}$ ), the region is highly enriched in LINE sequences $(46.08 \%$ of LINEs compared to the average content of the X chromosome of $31.81 \%)$, and relatively poor in SINEs $(6.12 \%$ compared to $10.18 \%$ of the whole $\mathrm{X}$ chromosome).

Within the POF CR1, a "POF breakpoint cluster" was mapped to a $1.8 \mathrm{Mb}$ genomic region (from 84.4-86.2 Mb of the $\mathrm{X}$ chromosome) between the $P O F 1 B$ gene and the $3^{\prime}$ flanking region of the $D A C H 2$ gene. ${ }^{7}$ Compared to the surrounding area, it is enriched in LINE repeats (60.4\%) and characterised by the lowest gene density (1.66 genes/Mb). Genes are large (from 102.434-684.143 Kb with an average gene length of $323.290 \mathrm{~Kb}$ ) and cover about $50 \%$ of the sequence. In addition, the region has a low GC (36.6\%) and CpG (1.4/Mb) content.

The genome organisation was compared with $1 \mathrm{Mb}$ regions flanking two autosomal breakpoints in 1 p35.3 and 2 q14.2 described in POF patients. ${ }^{\text {F }}$ For both autosomal regions we considered 0.98 and $0.93 \mathrm{Mb}(0.4 \mathrm{Mb}$ on both sides of the breakpoints). The two autosomal regions were very different from that on the X chromosome. Both were gene dense (18 and 8 genes/Mb) containing smaller genes. Both had a high GC content $(50 \%$ and $42.6 \%)$ and many $\mathrm{CpG}$ islands could be recognised by sequence analysis (25 and 11 , respectively). As in other GC rich regions, the number of LINE repeats was reduced (15\% and $37.5 \%$ ) compared to the SINEs $(62 \%$ and $18 \%)$.

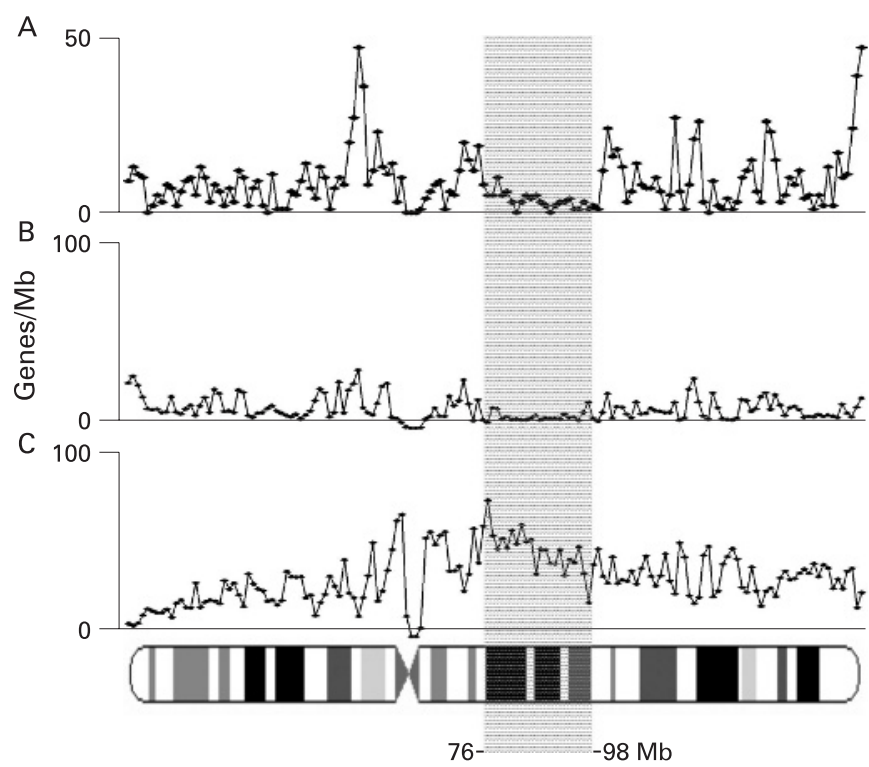

Figure 2 Genes and repeats content of the human $X$ chromosome, The number of (A) genes, (B) SINEs and (C) LINEs/Mb was calculated for the whole of $X$ chromosome as described in Material and methods. The number of SINEs and LINEs is represented as the percentage of the total number of repeats. The critical region 1 (CR1) is boxed. 
Global analysis of histone methylation of the POF CR1

The features outlined in the previous section suggested that the POF CR1 may be an heterochromatic region. Since a large number of modifications of the $\mathrm{N}$-terminal tails of histones are implicated in regulation of the chromatin state and in the establishment of global chromatin environment ${ }^{23}{ }^{24}$ we analysed recently produced dataset from high resolution whole genome profiling of histone methylation. ${ }^{21}$ The data derives from Solexa IG sequencing of IP DNA from human blood cells mononucleosomes prepared using $\mathrm{Ab}$ to several methylated histones. To determine the level of the different histone methylations along the $\mathrm{X}$ chromosomes, we calculated both the number of positions/Mb where $>1$ DNA fragment was sequenced (grey lines in figure 3), as well as the total number of Tags/ $\mathrm{Mb}$, that represents the level of each chromatin modification/ $\mathrm{Mb}$ (black lines in figure 3). As shown in figure $3 \mathrm{~A}$, the pattern of $2 \mathrm{MK} 4 \mathrm{H} 3$, the histone modification associated with active chromatin showed that most of the POF CR1 (from $86 \mathrm{Mb}$ to $94 \mathrm{Mb}$ ) was not modified by $2 \mathrm{MK} 4 \mathrm{H} 3$. Similar results were obtained for other active chromatin methylations, such as $3 \mathrm{MK} 4 \mathrm{H} 3$ and $1 \mathrm{MK} 4 \mathrm{H} 3$ (not shown).

From the dataset, we were able to obtain data on $\mathrm{K} 9 \mathrm{H} 3$, K27H3 and other histone methylations characteristic of silent chromatin that could be enriched in a region devoid of active chromatin modifications: the region between 88-91 Mb, corresponding to the Xq21 pseudoautosomal region (found only in human), was always devoid of any of the chromatin modifications tested. But also the surrounding portions of CR1 were free of most histone modifications studied (as an example see $3 \mathrm{MK} 27 \mathrm{H} 3$ in figure 3D). They were, however, particularly enriched in $2 \mathrm{MK} 9 \mathrm{H} 3$ and $3 \mathrm{MK} 9 \mathrm{H} 3$ (figure $3 \mathrm{E}, \mathrm{F}$ ) in respect to the rest of the $\mathrm{X}$ chromosome, confirming the heterochromatic nature of the region, but also the specificity of the chromatin organisation.

Interestingly, the whole region was also low in CTCF binding sites (figure $3 \mathrm{~B}$ ). Two clusters of CTCF binding sites were the chromatin organisation of CR1. We took advantage of a

mapped flanking CR1 (figure 3C): one, at 77-78 Mb, contained 209 tags; the second, at 99-100 Mb, contained 192.5 tags. The concentration of CTCF sites between the two peaks was much lower $(56.85 \mathrm{tags} / \mathrm{Mb})$ and suggested the presence of a large and homogeneous domain of heterochromatin spanning the CR1.

Similar results were obtained with the analysis of similar datasets from mouse cells (ES or MEF), on 3MK4H3, 3MK27H3 and $\mathrm{CTCF},{ }^{25}$ indicating that the organisation described for the human CR1 is an evolutionary conserved feature of the mammalian genomes.

\section{Comparison of the chromatin modification of CR1 and of autosomal breakpoint regions involved in POF}

The genome organisation found at the POF "breakpoint cluster" and at the autosomal breakpoint regions may underscore a different pattern of gene expression and chromatin organisation.

We have previously reported that the three genes in the CR1 "breakpoint cluster" (POF1B,CHM and DACH2) had low expression in human tissues. ${ }^{9}$ Analysis of the SymAtlas database demonstrated that it was also the same in the mouse and that most genes flanking the autosomal breakpoints were instead expressed at a relatively high level (not shown).

We then compared the chromatin organisation of comparable size portions of the three chromosomal regions by chromatin immunoprecipitation (ChIP) and microarray hybridisation (ChIP on chip) to look for long range chromatin modifications. We prepared a dense BAC array containing overlapping BACs (supplemental table $\mathrm{S} 1$ available online) corresponding to $1 \mathrm{Mb}$ of chromosome $1 \mathrm{p} 35.3$ and chromosome 2q14.2, and about $4 \mathrm{Mb}$ of the $\mathrm{X}$ chromosome around the POF "breakpoint cluster" (figure 4). The array was hybridised to chromatin prepared from a female lymphoblastoid cell line immunoprecipitated with $\mathrm{Ab}$ to the three most common histone modifications of active chromatin: $2 \mathrm{MK} 4 \mathrm{H} 3, \mathrm{AcH} 4$ and $\mathrm{AcH} 3$. The silent chromatin modifications (3MK27H3, 2MK9H3 and 3MK9H3) were barely detectable in lymphoblastoid cells (not shown) and

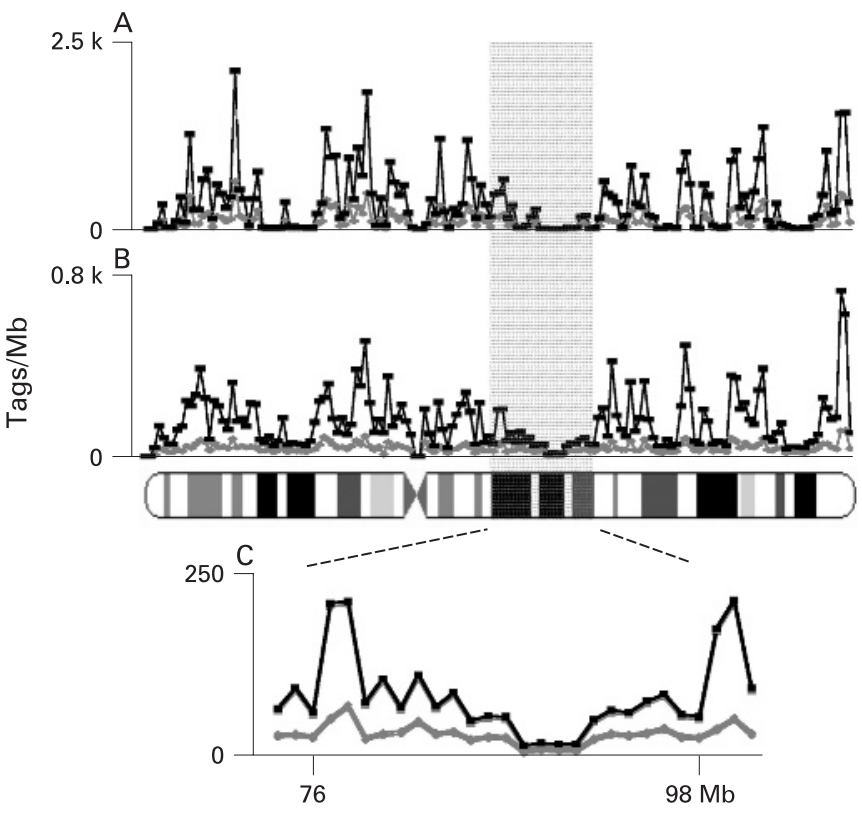

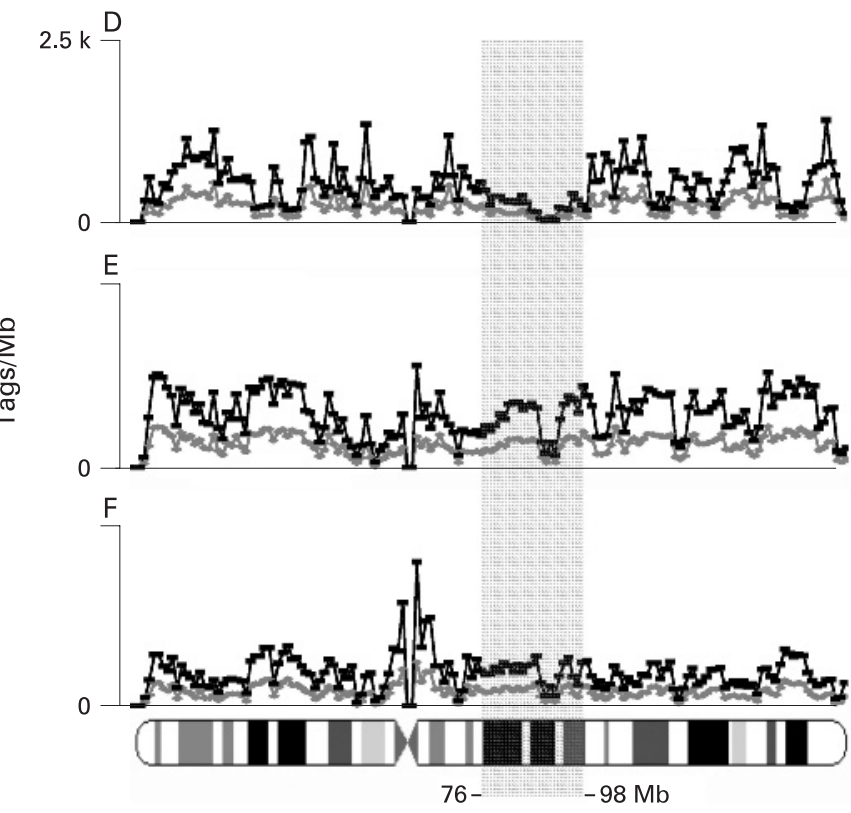

Figure 3 Histone methylations along the human $X$ chromosome. The total number of sequenced Tags/Mb (black) and number of positions occupied by Tags (grey) along the human $\mathrm{X}$ chromosome was calculated from Barski et $a^{21}$ as described in Materials and methods. Chromatin immunoprecipitation (IP) was with antibodies to (A) 2MK4H3, (B) CTCF, (D) 3MK27H3, (E) 2MK9H3 and (F) 2MK9H3. (C) Enlargement of the CTCF binding sites in the critical region 1 (CR1). The CR1 is boxed. 

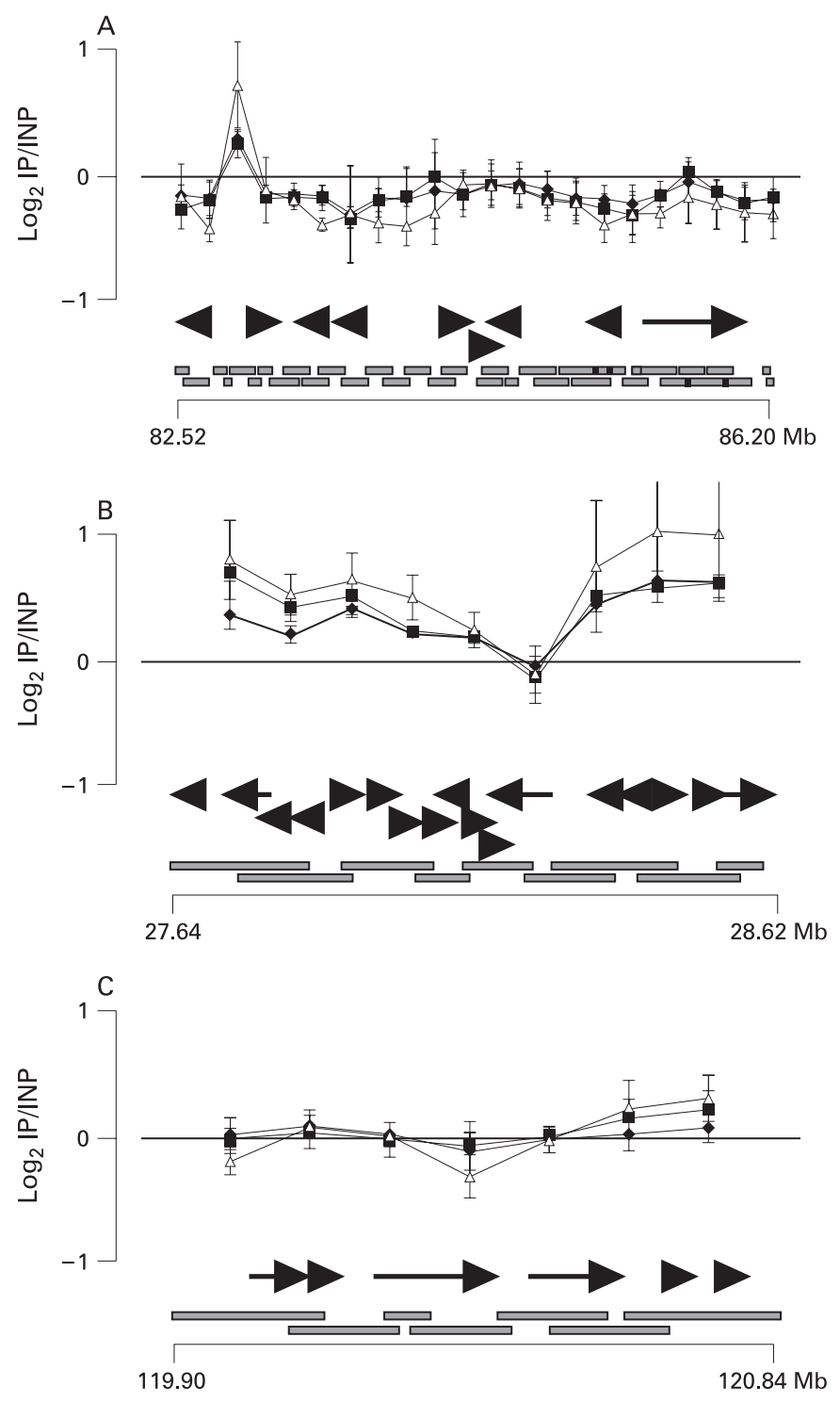

Figure 4 Chromatin immunoprecipitation (ChIP) on chip with bacterial artificial chromosome (BAC) arrays. BACs from the $X(A), 1$ (B) and 2 (C) chromosome regions, involved in premature ovarian failure (POF) associated translocations, were hybridised to DNAs obtained by ChIP with anti-AcH3 (black diamonds), anti-AcH4 (black squares) or anti$2 \mathrm{MK} 4 \mathrm{H} 3$ (white triangles). The $\log _{2} \mathrm{IP} /$ input is shown above a representation of the gene map of each region: horizontal arrows indicate gene orientation. BACs and map positions are represented at the bottom. Only the data for one of the two dye combinations are shown: the opposite dye combination gave identical results.

could not be studied. The hybridisation values of the IP DNA to each $\mathrm{X}$ chromosome BAC were consistent with the low level $2 \mathrm{MK} 4 \mathrm{H} 3$ previously demonstrated in blood cells. Most of the normalised hybridisation values to $\mathrm{X}$ chromosome BACs (95.4\%, 86.4\% and $95.4 \%$ of the values for $\mathrm{AcH} 3, \mathrm{AcH} 4$ and $2 \mathrm{MK} 4 \mathrm{H} 3$, respectively) were on the negative side of the curve in figure $4 \mathrm{~A}$ and showed that the active chromatin modifications were few in this part of the genome. The opposite was the case for the chromosome 1 region: most of the $\mathrm{BAC}$ clones gave a positive hybridisation value to the three ChIP preparations (figure $4 \mathrm{~B}$ ), showing enrichment in histone acetylation and $2 \mathrm{MK} 4 \mathrm{H} 3$. A less evident but positive enrichment could be detected on chromosome 2 . In this genomic region most normalised values were only just above zero, suggesting a more limited enrichment in active chromatin modifications (figure 4C).

The histone modifications studied mainly occurred at the promoters of active genes. To exclude the possibility that the pattern detected could be ascribed to gene or promoter density, we analysed active chromatin modifications of the putative promoters of all the genes flanking each breakpoint. The analysis was done by real-time PCR of ChIP products obtained from at least two different normal lymphoblastoid cell lines. Primers were designed in the promoter regions of each gene flanking for about $1 \mathrm{Mb}$ the $\mathrm{X}$ chromosome breakpoint cluster (from APOOL to DACH2) and the two autosomes (from RPA2 to DNAJC8 at 1p35.3; from LOC200373 to INHBB at 2p14.2). We could demonstrate enrichment in chromatin modifications at the putative promoters of five of the seven $\mathrm{X}$ chromosome genes, of all six genes of chromosome 1 , and six of the seven genes of chromosome 2 . In all such cases two to three primer pairs within a $1 \mathrm{~kb}$ region were used to confirm the results. Supplemental figure S1 (available online) shows the results obtained with the LB696 cell line, used also for the global analysis. The fold increase of the ChIP over the input DNA was low for the X chromosome gene promoters (supplemental figure S1a available online) and much higher at the autosomal gene promoters (supplemental figure $\mathrm{S} 1 \mathrm{~b}, \mathrm{c}$ available online). In agreement with the results of the global analysis, histone modifications were highly enriched at the promoters of the chromosome 1 gene and less at the promoters of the chromosome 2 genes. We can conclude that the $\mathrm{X}$ chromosome and the autosomal regions involved in POF associated $\mathrm{X} ; \mathrm{A}$ breakpoints have a different gene activity and genomic organisation, the $\mathrm{X}$ chromosome presenting a heterochromatic conformation and the two autosomal regions a euchromatic one.

\section{Active chromatin modifications in POF patient lymphoblasts}

As the heterochromatic state of CR1 and the euchromatic state of the autosomal regions involved in POF could be detected in lymphoblastoid cell lines, we tested whether we could also demonstrate the position effect hypothesised. ${ }^{9}$ Using the BAC array, we analysed chromatin IP preparations from lymphoblastoid cells of the two POF patients (LA1 and LB106) carrying the $\mathrm{X} ; 1$ and $\mathrm{X} ; 2$ rearrangements. We found no difference between patients and normal control lymphoblastoid cell lines (data not shown), suggesting that under these conditions there is no long range effect of the translocation.

In the same patients, we also analysed the putative promoters of each gene flanking the X;A breakpoints as described in the previous section, by real time PCR of the ChIP preparations. In each genomic region, we analysed one patient and four normal controls (supplemental table S2 available online). Since we had to compare chromatin modifications in cell lines presenting different global modification levels (not shown), fold increase in ChIP over input DNA was normalised by calculating the ratio between each independent modification at each point and for each cell line (the complete dataset is reported in supplemental table S2). In each genomic region, cell lines from POF patients carrying a balanced translocation in a different region were also analysed: in all instances results were identical to the normal cell lines, thus demonstrating that the POF patients' cell lines did not carry a generalised alteration in chromatin organisation. The POF breakpoint cluster region on the $\mathrm{X}$ chromosome did not present any consistent difference in histone modification in any of the patients analysed (not shown). On the other hand, in 

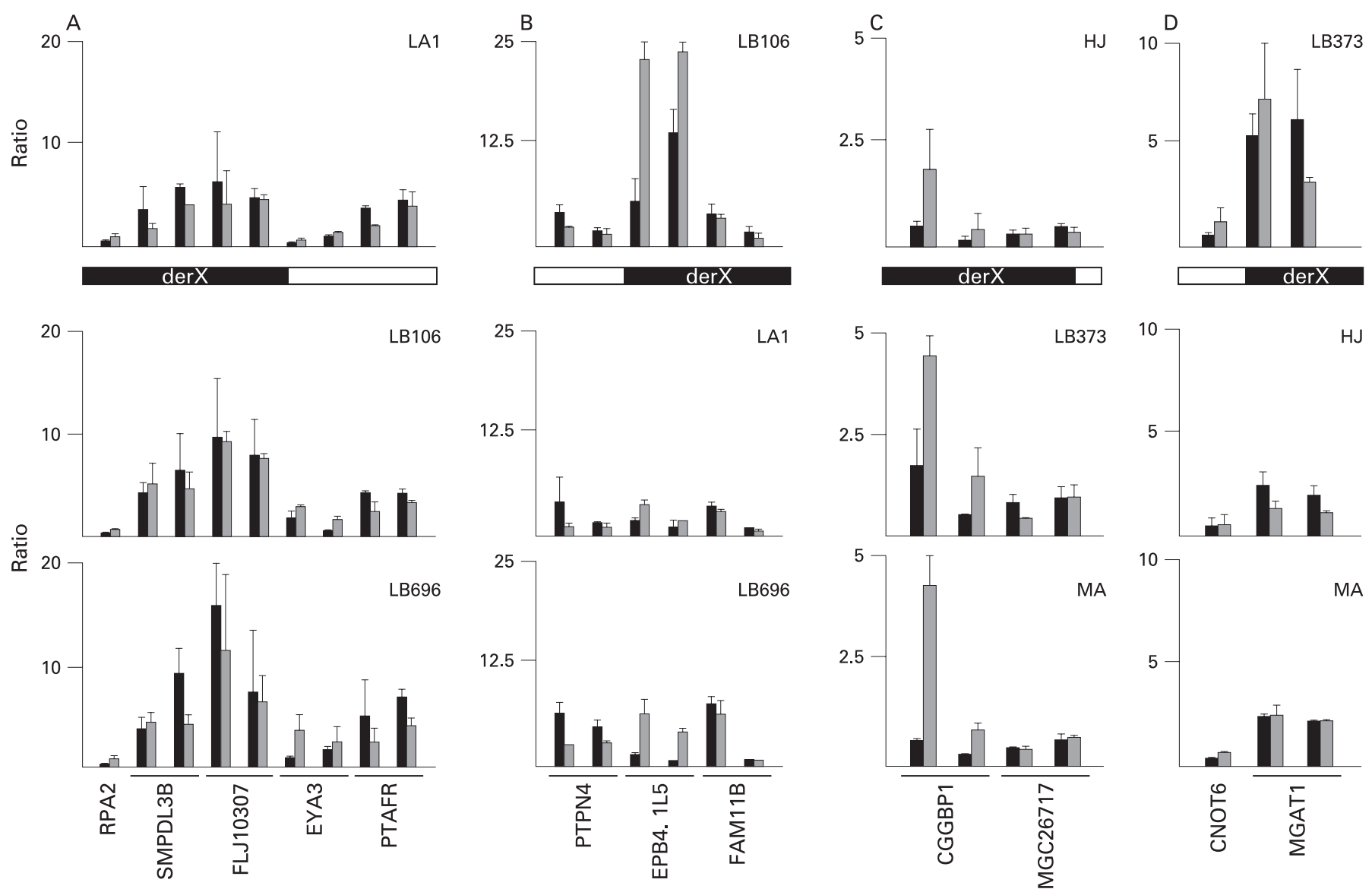

Figure 5 Chromatin modification analysis at the promoters of autosomal genes involved in premature ovarian failure (POF) associated balanced translocations. Fold increase of chromatin immunoprecipitation (ChIP) over input DNA was calculated as described in Materials and methods and normalised by calculating the ratio between 2MK4 (black) or $\mathrm{AcH} 4$ (slashed) with $\mathrm{AcH} 3$ at each point and for each cell line. Real-time polymerase chain reaction (PCR) was done with primers in the $5^{\prime}$ region of the genes indicated. Data are reported in supplemental table $S 1$. A-D correspond to the four autosomal regions: (A) 1p35.3; (B) 2q14.2; (C) 3p21; (D) 5q35. On top is the patient cell line; below is a schematic representation of each breakpoint and ChIP analysis of the two control cell lines indicated.

patient lymphoblastoid cell lines, $2 \mathrm{MK} 4 \mathrm{H} 3$ was altered at the promoters of some of the autosomal genes (figure 5).

In $1 \mathrm{p} 35.3$, changes in $2 \mathrm{MK} 4 \mathrm{H} 3$ modification could be detected at the promoter of the two genes FLJ10307 and $S M P D L 3 B$, translocated to the $\operatorname{der} \mathrm{X}$ in the patient (figure $5 \mathrm{~A}$, supplemental table S2). In 2 q14.2, $2 \mathrm{MK} 4 \mathrm{H} 3$ was particularly increased at the $5^{\prime}$ end of EPB4.1L5, that was also translocated to the derX in the patient (figure 5B, supplemental table S2). In both instances the normalised values of $2 \mathrm{MK} 4 \mathrm{H} 3$ modification for the genes indicated were either increased or decreased more than twice in patients compared to controls, while they were almost identical for the other genes in the region. This is shown in table 1 where the ratio between the normalised fold increase in patients and the average value of four normal lymphoblastoid cell controls is shown. The value for $2 \mathrm{MK} 4 \mathrm{H} 3$ is around 0.5 (0.41-0.69) in SMPDL3B and FLJ10307 and ranges from 1.9811.58 for EPB4.1L5. It is 1 for all the other genes, that appeared thus unchanged in patient lymphoblasts. Therefore, in patient lymphoblasts, the change in the level of $2 \mathrm{MK} 4 \mathrm{H} 3$ appears quite relevant, considering that only one chromosome was affected.

To confirm the observed position effect we analysed as described above the promoters of all the genes found at two additional autosomal regions involved in X;autosome translocations. The HJ patient carried a breakpoint in $3 \mathrm{p} 21,2 \mathrm{Mb}$ from the centromere, and patient LB373 in 5q35. ${ }^{9}$ None interrupted a gene, but both interrupted a gene rich region. Both promoters at
3 p21 and the promoter of the MGAT1 gene in $5 \mathrm{q} 35$ were altered compared to controls (figure 5C,D, table 1).

No changes in histone modifications could be detected by this analysis at the $5^{\prime}$ end of some of the genes: a number of additional breakpoints should be analysed to explain why only some genes and possibly at one side of each breakpoint seem to be affected by the translocation as well as why the histone modification is in some cases decreased (see SMPDL3B, FLJ10307, CGGBP1 and MGC26717 in figure 5A,C) and in others it is increased (see EPB4.1L5 and MGAT1 in figure 5B,D).

A common feature of all cases studied is the limited alteration in the chromatin modification pattern in the patient as only one of the active chromatin modifications analysed appeared affected. The results suggest that transcriptional regulation in lymphoblastoid cells may not be greatly changed. In two cases (MGAT1 and SMPDL3B) we could determine by allele specific real-time RT-PCR whether the chromatin change had altered gene expression. In both cases it was not the case (not shown).

\section{DISCUSSION}

In this paper we demonstrate an epigenetic effect of the active $\mathrm{X}$ chromosome on the promoters of genes translocated next to the POF CR1 and give support to our previous suggestion that POF in X; autosome balanced translocations is due to a position effect of CR1 on translocated autosomal genes. ${ }^{9}$ We also show a 
Table 1 Variation in 2MK4 in premature ovarian failure (POF) patients

\begin{tabular}{|c|c|c|c|}
\hline Gene & Primers & 2MK4* & $\mathrm{AcH}^{*}{ }^{*}$ \\
\hline \multicolumn{4}{|l|}{$1 p 35.3$} \\
\hline RPA2 & RPA2 F3/R3 & 1.47 & 1.11 \\
\hline SMPDL3B & ASMLC F1/R1 & 0.55 & 1.34 \\
\hline SMPDL3B & ASMLCF/R & 0.53 & 0.86 \\
\hline FLJ10307 & NM018LC-F2/R2 & 0.56 & 0.88 \\
\hline FLJ10307 & NM018LCF/R & 0.69 & 0.85 \\
\hline FLJ10307 & NM018-F1/R1TRIS & 0.56 & 1.06 \\
\hline EYA3 & EYALC-F/R & 0.41 & 1.44 \\
\hline EYA3 & EYALC-F2/R2 & 1.16 & 1.61 \\
\hline PTAFR & PTAFLC-F1/R1 & 0.89 & 1.11 \\
\hline PTAFR & $29.5-\mathrm{F} / \mathrm{R}$ & 0.94 & 0.84 \\
\hline DNAJC8 & IPJC8-F1/R1 & 1.36 & 1.06 \\
\hline \multicolumn{4}{|l|}{$2 q 14.2$} \\
\hline PTPN4 & PTP-F2/R2 & 0.82 & 0.58 \\
\hline PTPN4 & PTPLC-F3/R3 & 0.74 & 0.70 \\
\hline EPB4.1L5 & EPBLC-F1/R1 & 2.87 & 0.73 \\
\hline EPB4. $1 \angle 5$ & EPBLC-F/R & 11.58 & 1.42 \\
\hline FAM11B & IPFAM11B-F/R & 0.67 & 0.76 \\
\hline FAM11B & IPFAM-F2/R2 & 1.73 & 1.16 \\
\hline$R A L B$ & $96.7-\mathrm{F} / \mathrm{R}$ & 0.87 & 1.09 \\
\hline \multicolumn{4}{|l|}{$3 p 21$} \\
\hline CGGBP1 & IP CGGBP1 F/R & 0.73 & 0.95 \\
\hline CGGBP1 & CGGBP1LC-F2/R2BIS & 0.55 & 1.16 \\
\hline CGGBP1 & CGGBP1LC-F3/R3BIS & 0.42 & 1.28 \\
\hline MGC26717 & MGC267LC-F2/R2 & 0.65 & 1.20 \\
\hline MGC26717 & IP MGC26717 F1/R1 & 0.54 & 0.69 \\
\hline MGC26717 & MGC267LC-F3/R3 BIS & 0.65 & 1.32 \\
\hline \multicolumn{4}{|l|}{$5 q 35$} \\
\hline CNOT6 & IP CC4L F1/CNOT6IP-R & 1.13 & 1.08 \\
\hline MGAT1 & IP MGAT1 F/R & 1.94 & 0.97 \\
\hline MGAT1 & MGAT1LC-F2/R2 & 2.63 & 1.50 \\
\hline MGAT1 & MGAT1LC-F3/R3 & 1.70 & 0.90 \\
\hline
\end{tabular}

*The normalised fold change values in each POF patient was divided by the average values of four controls.

2MK4 and $\mathrm{AcH} 4$ were normalised for $\mathrm{AcH} 3$.

The values for genes showing 2MK4 alterations are in bold.

peculiar heterochromatic organisation of the CR1, which underscores structural and/or functional roles for this large portion of the mammalian X chromosome.

The POF CR1 is gene poor region, highly enriched in repetitive sequences and particularly in LINE retrotransposons. The heterochromatic nature of the POF CR1 was confirmed by the results on histone modifications in somatic cells as well as by gene expression analysis. The whole CR1 was devoid of most active chromatin modifications analysed, while it appeared uniquely enriched in $2 \mathrm{MK} 9 \mathrm{H} 3$ and $3 \mathrm{MK} 9 \mathrm{H} 3$, markers of silent heterochromatin and of centromeres. ${ }^{23}$ The organisation of the POF CR1 is also reminiscent of the centromeres for several other of its characteristics: the $\mathrm{A} / \mathrm{T}$ rich base composition, the high content of LINE repeats, and the very low meiotic recombination frequency. ${ }^{26}$ We can hypothesise that, as it was shown for centromeres, RNAi encoded by the repeats in the region may be involved in nucleation of heterochromatin and eventually binding of HP1, for the maintenance of the heterochromatic state..$^{27}$

We also show that the whole region was flanked by two peaks of CTCF binding sites, in human and in the mouse, and appeared instead quite devoid of CTCF binding sites. CTCF is a ubiquitously expressed and highly conserved protein, implicated in the establishment of insulators, the elements that in vertebrates prevent the spreading of heterochromatin and restrict transcriptional enhancers from activating unrelated promoters. ${ }^{28} 29$ This finding confirms the large and homogeneous chromatin domain and underscores a structural role for the region. The relative vicinity of CR1 to the XIC suggests a role for the region in this process, possibly at the $\mathrm{X}$ chromosome pairing and counting, one of the earliest events in X chromosome inactivation. ${ }^{30}{ }^{31}$ Whether this may be related to the exceptional enrichment in LINE sequences of the CR1, as it was proposed by others, ${ }^{32-34}$ is an open question.

Until now, we were unable to study directly chromatin of the CR1 in oocytes or in somatic cells of the ovary; however, based on the profound downregulation of gene expression observed along CR1, up to the fertilised egg stage and to completion of meiosis, and on its low meiotic recombination frequency, it is unlikely that in oocytes CR1 may lose the heterochromatic organisation. Instead, it may acquire an oocyte specific organisation, possibly through binding of oocyte specific histone variants, that enables the transition to transcriptional quiescence and chromatin condensation and contributes to maintaining the observed inhibition of gene expression throughout meiosis. Much of the evidence and the mouse mutants suggest that this may be the case and that specific histone modifications characterise germ cell chromatin. Chromatin alterations in germ cells have been shown to produce severe consequences in progression through meiosis and oocyte maturation. ${ }^{13} 1435$ Moreover, in the germ line, active transposition is potentially mutagenic and it is not surprising that the genomes have evolved specific mechanisms to control the activity of transposable elements in this cell type. ${ }^{27}$

When the highly heterochromatic and transcriptionally silent DNA of CR1 in oocytes is joined to euchromatic autosomal regions enriched in ovary and oocyte expressed genes, it is likely that one of the two chromatin organisations may spread into the other. In Drosophila position effect variegation, translocation next to a heterochromatic region will result in gene inactivity. ${ }^{36}$ In humans, few such examples have been described. One is the limited spreading of $\mathrm{X}$ chromosome inactivation to autosomes in X;A translocations. ${ }^{37} \mathrm{~A}$ second example is the long distance silencing effect of short telomeric repeats in fascioscapulohumeral muscular dystrophy. ${ }^{38}$

Analysis of the chromatin modification of the promoters of the genes flanking the breakpoints for about $1 \mathrm{Mb}$ demonstrated changes in chromatin composition of autosomal gene promoters. Such changes were specific of the breakpoint regions and not found elsewhere in the patients. They confirmed the position effect. In lymphoblastoid cells, among the three chromatin modifications analysed, only one was changed and in the two cases where it could be studied the gene expression was not modified.

In conclusion, the results show that translocation to CR1 is able to modify the chromatin of autosomal genes in somatic cells, but that this is not sufficient to delete all active chromatin modifications and alter gene expression. This may, however, occur in oocytes where downregulation of gene expression is more evident and widespread, and can account for the specificity of the POF phenotype. Our results support the hypothesis of a role for CR1 in the downregulation of oocyte expressed genes during oocyte and ovarian follicle maturation and of the X linked POF as an epigenetic disorder. Analysis of the autosomal breakpoint regions in patients carrying X;A balanced translocations interrupting CR1 may therefore be a novel tool to identify candidate genes for POF.

Acknowledgements: We thank the patients for agreeing to contribute to this research and our colleagues for many helpful discussions during this work.

Funding: This work was supported by MIUR-FIRB RBNE0189HM 005 and Telethon Italy.

Competing interests: None declared.

Patient consent: Obtained. 
FR's present address is Sbarro Institute for Cancer Research and Molecular Medicine, Temple University, Philadelphia, Pennsylavania, USA.

TP's present address is Departments of Pediatrics and Medicine, UCSD School of Medicine, La Jolla, California, USA.

Provenance and peer review: Not commissioned; externally peer reviewed.

\section{REFERENCES}

1. Zinn AR, Ross JL. Turner syndrome and haploinsufficiency. Curr Opin Genet Dev 1998:8:322-7.

2. Sybert VP, McCauley E. Turner's syndrome. N Engl J Med 2004;351:1227-38.

3. Anasti JN. Premature ovarian failure: an update. Fertil Steril 1998;70:1-15.

4. Goswami D, Conway G. Premature ovarian failure. Human Reproduction Update 2005; 11:391-410.

5. Toniolo D. X-linked premature ovarian failure: a complex disease. Curr Opin Genet Dev 2006;16:293-300.

6. Therman E, Laxova R, Susman B. The critical region on the human Xq. Hum Genet 1990;85:455-61.

7. Rizzolio F, Bione S, Sala C, Goegan M, Gentile M, Gregato G, Rossi E, Pramparo T, Zuffardi $\mathrm{O}$, Toniolo D. Chromosomal rearrangements in $\mathrm{Xq}$ and premature ovarian failure: mapping of 25 new cases and review of the literature. Hum Reprod 2006;21:1477-83.

8. Khil PP, Smirnova NA, Romanienko PJ, Camerini-Otero RD. The mouse $X$ chromosome is enriched for sex-biased genes not subject to selection by meiotic sex chromosome inactivation. Nat Genet 2004;36:642-6.

9. Rizzolio F, Sala C, Alboresi S, Bione S, Gilli S, Goegan M, Pramparo T, Zuffardi O, Toniolo D. Epigenetic control of the critical region for premature ovarian failure on autosomal genes translocated to the $\mathrm{X}$ chromosome: a hypothesis. Hum Genet 2007:121:441-50.

10. Pan H, O'Brien MJ, Wigglesworth K, Eppig JJ, Schultz RM. Transcript profiling during mouse oocyte development and the effect of gonadotropin priming and development in vitro. Dev Biol 2005;286:493-506.

11. Nguyen DK, Disteche CM. Dosage compensation of the active $X$ chromosome in mammals. Nat Genet 2006;38:47-53.

12. Cheng MK, Disteche CM. A balancing act between the $\mathrm{X}$ chromosome and the autosomes. J Biol 2006;5:2.

13. Hayashi K, Yoshida K, Matsui Y. A histone H3 methyltransferase controls epigenetic events required for meiotic prophase. Nature 2005;438:374-8.

14. Tachibana M, Nozaki M, Takeda N, Shinkai Y. Functional dynamics of H3Kg methylation during meiotic prophase progression. Embo J 2007:26:3346-59.

15. Wallrath LL, Elgin SC. Position effect variegation in Drosophila is associated with an altered chromatin structure. Genes Dev 1995;9:1263-77.

16. Schotta G, Ebert A, Dorn R, Reuter G. Position effect variegation and the genetic dissection of chromatin regulation in Drosophila. Semin Reprod Med 2003;14:67-75.

17. Gilbert N, Boyle S, Fiegler H, Woodfine K, Carter NP, Bickmore WA. Chromatin architecture of the human genome: gene-rich domains are enriched in open chromatin fibers. Cell 2004;118:555-66

18. Pramparo T, Mattina T, Gimelli S, Liehr T, Zuffardi 0. Narrowing the deleted region associated with the 15q21 syndrome. Eur J Med Genet 2005;48:346-52.

19. Litt MD, Simpson M, Recillas-Targa F, Prioleau MN, Felsenfeld G. Transitions in histone acetylation reveal boundaries of three separately regulated neighboring loci. Embo J 2001;20:2224-35

20. Su Al, Cooke MP, Ching KA, Hakak Y, Walker JR, Wiltshire T, Orth AP, Vega RG, Sapinoso LM, Mogrich A, Patapoutian A, Hampton GM, Schultz PG, Hogenesch JB. Large-scale analysis of the human and mouse transcriptomes. Proc Natl Acad Sci USA 2002;99:4465-70.

21. Barski A, Cuddapah S, Cui K, Roh TY, Schones DE, Wang Z, Wei G, Chepelev I, Zhao $\mathrm{K}$. High-resolution profiling of histone methylations in the human genome. Cell 2007;129:823-37.

22. Waterston RH, Lindblad-Toh K, Birney E, Rogers J, Abril JF, Agarwal P, Agarwala R, Ainscough R, Alexandersson M, An P, Antonarakis SE, Attwood J, Baertsch R, Bailey J, Barlow K, Beck S, Berry E, Birren B, Bloom T, Bork P, Botcherby M, Bray N, Brent MR, Brown DG, Brown SD, Bult C, Burton J, Butler J, Campbell RD, Carninci P, Cawley S, Chiaromonte F, Chinwalla AT, Church DM, Clamp M, Clee C, Collins FS, Cook LL, Copley RR, Coulson A, Couronne 0, Cuff J, Curwen V, Cutts T, Daly M, David R, Davies J, Delehaunty KD, Deri J, Dermitzakis ET, Dewey C, Dickens NJ, Diekhans M, Dodge S, Dubchak I, Dunn DM, Eddy SR, Elnitski L, Emes RD, Eswara P, Eyras E,
Felsenfeld A, Fewell GA, Flicek P, Foley K, Frankel WN, Fulton LA, Fulton RS, Furey TS Gage D, Gibbs RA, Glusman G, Gnerre S, Goldman N, Goodstadt L, Grafham D, Graves TA, Green ED, Gregory S, Guigo R, Guyer M, Hardison RC, Haussler D, Hayashizaki Y, Hillier LW, Hinrichs A, Hlavina W, Holzer T, Hsu F, Hua A, Hubbard T, Hunt A, Jackson I. Jaffe DB, Johnson LS, Jones M, Jones TA, Joy A, Kamal M, Karlsson EK, Karolchik D, Kasprzyk A, Kawai J, Keibler E, Kells C, Kent WJ, Kirby A, Kolbe DL, Korf I, Kucherlapati RS, Kulbokas EJ, Kulp D, Landers T, Leger JP, Leonard S, Letunic I, Levine R, Li J, Li M, Lloyd C, Lucas S, Ma B, Maglott DR, Mardis ER, Matthews L, Mauceli E, Mayer JH, McCarthy M, McCombie WR, McLaren S, McLay K, McPherson JD, Meldrim J, Meredith B, Mesirov JP, Miller W, Miner TL, Mongin E, Montgomery KT, Morgan M, Mott R, Mullikin JC, Muzny DM, Nash WE, Nelson JO, Nhan MN, Nicol R, Ning Z, Nusbaum C, O'Connor MJ, Okazaki Y, Oliver K, Overton-Larty E, Pachter L, Parra G, Pepin KH, Peterson J, Pevzner P, Plumb R, Pohl CS, Poliakov A, Ponce TC, Ponting CP, Potter S, Quail M, Reymond A, Roe BA, Roskin KM, Rubin EM Rust AG, Santos R, Sapojnikov V, Schultz B, Schultz J, Schwartz MS, Schwartz S, Scott C, Seaman S, Searle S, Sharpe T, Sheridan A, Shownkeen R, Sims S, Singer JB Slater G, Smit A, Smith DR, Spencer B, Stabenau A, Stange-Thomann N, Sugnet C, Suyama M, Tesler G, Thompson J, Torrents D, Trevaskis E, Tromp J, Ucla C, UretaVidal A, Vinson JP, Von Niederhausern AC, Wade CM, Wall M, Weber RJ, Weiss RB, Wendl MC, West AP, Wetterstrand K, Wheeler R, Whelan S, Wierzbowski J, Willey D, Williams S, Wilson RK, Winter E, Worley KC, Wyman D, Yang S, Yang SP, Zdobnov $\mathrm{EM}$, Zody MC, Lander ES. Initial sequencing and comparative analysis of the mouse genome. Nature 2002;420:520-62.

23. Kouzarides T. Chromatin modifications and their function. Cell 2007:128:693-705

24. Bernstein BE, Meissner A, Lander ES. The mammalian epigenome. Cell 2007:128:669-81.

25. Mikkelsen TS, Ku M, Jaffe DB, Issac B, Lieberman E, Giannoukos G, Alvarez P Brockman W, Kim TK, Koche RP, Lee W, Mendenhall E, O'Donovan A, Presser A, Russ C, Xie X, Meissner A, Wernig M, Jaenisch R, Nusbaum C, Lander ES, Bernstein $B E$. Genome-wide maps of chromatin state in pluripotent and lineage-committed cells. Nature 2007:448:553-60

26. Kong A, Gudbjartsson DF, Sainz J, Jonsdottir GM, Gudjonsson SA, Richardsson B, Sigurdardottir S, Barnard J, Hallbeck B, Masson G, Shlien A, Palsson ST, Frigge ML, Thorgeirsson TE, Gulcher JR, Stefansson K. A high-resolution recombination map of the human genome. Nat Genet 2002;31:241-7.

27. Slotkin RK, Martienssen R. Transposable elements and the epigenetic regulation of the genome. Nat Rev Genet 2007;8:272-85.

28. Felsenfeld G, Burgess-Beusse B, Farrell C, Gaszner M, Ghirlando R, Huang S, Jin C Litt M, Magdinier F, Mutskov V, Nakatani Y, Tagami H, West A, Yusufzai T. Chromatin boundaries and chromatin domains. Cold Spring Harb Symp Quant Biol 2004:69:245-50

29. Kim TH, Abdullaev ZK, Smith AD, Ching KA, Loukinov DI, Green RD, Zhang M0, Lobanenkov WV, Ren B. Analysis of the vertebrate insulator protein CTCF-binding sites in the human genome. Cell 2007;128:1231-45.

30. Lee JT. Regulation of X-chromosome counting by Tsix and Xite sequences. Science 2005;309:768-71.

31. $\mathbf{X u} \mathbf{N}$, Tsai CL, Lee JT. Transient homologous chromosome pairing marks the onset of $X$ inactivation. Science 2006;311:1149-52.

32. Bailey JA, Carrel L, Chakravarti A, Eichler EE. Molecular evidence for a relationship between LINE-1 elements and X chromosome inactivation: the Lyon repeat hypothesis. Proc Natl Acad Sci USA 2000;97:6634-9.

33. Lyon MF. LINE-1 elements and $X$ chromosome inactivation: a function for "junk" DNA? Proc Natl Acad Sci USA 2000;97:6248-9.

34. Hansen RS. $X$ inactivation-specific methylation of LINE-1 elements by DNMT3B: implications for the Lyon repeat hypothesis. Hum Mol Genet 2003:12:2559-67.

35. van der Heijden GW, Derijck AA, Posfai E, Giele M, Pelczar P, Ramos L, Wansink DG, van der Vlag J, Peters AH, de Boer P. Chromosome-wide nucleosome replacement and $\mathrm{H} 3.3$ incorporation during mammalian meiotic sex chromosome inactivation. Nat Genet 2007;39:251-8.

36. Schotta G, Ebert A, Krauss V, Fischer A, Hoffmann J, Rea S, Jenuwein T, Dorn R Reuter G. Central role of Drosophila SU(VAR)3-9 in histone H3-K9 methylation and heterochromatic gene silencing. Embo J 2002:21:1121-31.

37. Popova BC, Tada T, Takagi N, Brockdorff N, Nesterova TB. Attenuated spread of Xinactivation in an $\mathrm{X}$; autosome translocation. Proc Natl Acad Sci USA 2006:103:7706-11.

38. Gabellini D, Green MR, Tupler R. When enough is enough: genetic diseases associated with transcriptional derepression. Curr Opin Genet Dev 2004;14:301-7. 